\title{
Visual participatory methodology as a prompt for agentic creativity: Revealing views and visions of a teacher learning journey
}

\section{Margie Childs}

Faculty of Education, Nelson Mandela University, Port Elizabeth, South Africa

Margie.childs@mandela.ac.za

https://orcid.org/0000-0001-6872-8418

(Received: 3 February 2020; accepted: 8 September 2020)

\section{Abstract}

By using activities such as visual participatory methodologies, pre-service teachers and university staff members are able to explore and extend their ideas of what it means to be a teacher. In this research project, I sought to prompt a visual dialogue between students and staff. The distance provided when using creative enquiry procedures such as photo-voice, collage, and drawing allows participants, as members of a teaching community, to detach from their assumptions and view themselves, knowledge, and meaning making in more subtle ways. The aim of this creative participatory study was to explore dialogic engagement concerning the learning-toteach journey of Bachelor of Education (B Ed) students at a South African university. The visual-based interaction of student teachers and staff is revealed, and the movements towards the goal of teacherness laid bare. I make an argument for the use of visual and creative approaches as a means of collaboratively bridging complicated and difficult territory, moving beyond boundaries to spaces of creative action. An account of the potential of artful portrayals as both disruptive and coalescing devices is a key contribution of this enquiry.

Keywords: Visual participatory methodologies, agentic creativity, teacher learning, teacherness

\section{Introduction}

Visual- and arts-based approaches offer creative, collaborative spaces for surfacing complex understandings. Communities have opportunities to reflect, share their ideas, and, potentially, bring about transformation as they engage with participatory methodologies (Mitchell et al., 2017). In an Initial Teacher Education (ITE) context, student teachers and university staff have the prospect of engaging closely with each other as participants in a Teacher Learning Community. Pre-service teachers are able to explore and extend their ideas about what it means to be a teacher. Often, limited and limiting understandings of teaching are transferred during the shift from school to higher education (Feiman-Nemser, 2001; Wall, 2016) Creative 
approaches to meaning-making have the potential to prompt "multifaceted knowledge" (Van der Vaartet al., 2018, p. 1). The distance provided when using creative enquiry procedures such as photo-voice, collage, and drawing allows participants to detach themselves from their assumptions and view knowledge and meaning making in more subtle ways. A creative departure point can provide a stimulus for empowerment and substantial change (De Lange, 2008). Mannay has indicated that "visual[s] can act as a tool of de-familiarisation" (2014, p. 1). Deep thinking can, thus, be facilitated in arts-related research as Baden and Wimpenny ( 2014) have pointed out. The "inward and outward" journey towards the teacher-self unfolds over time (Conway \& Clark, 2003, p. 465). Aspects of the experiences of senior and firstyear students can be captured using visual methodologies so that students can learn from each other, and students and staff members can collectively design guiding maps for the Teacher Learning journey.

Feiman-Nemser (2001) proposed that learning to teach is a continuum that focusses particularly on initial preparation through to the early years of teaching after obtaining a qualification. Within the pre-service phase of professional learning, various stages can be discerned that can be used as what we might think of as stopping places to reflect on the learning-to-teach journey. The moments of contemplation in the learning-to-teach process that are used in this research are tagged as Bridging, Becoming, Being, and Belonging (BBBB). The notion of a continuum of learning is confirmed, and extended to include both introspection and engagement with others. (Huebner, 2009). Visual Participatory Methodologies (VPM) offer a creative space for enquiry (De Lange, 2008). Students and staff are able to discover, together, what it means to work towards a sense of belonging as a beginner teacher.

\section{Framing the journey}

The metaphor of a journey has been used extensively regarding Teacher Learning (Ayers, 2015). The first part of this learning journey has both informal and formal components (Feiman-Nemser, 2001). It begins as a learner in school, before registration for a teaching qualification and ends, after a period of study, in certification. Personal and professional learning in pre-service years as a key goal of teacher education and reflection is an important element of Teacher Learning (Rauduvaita et al., 2015).

Opportunities to pause and reflect can offer powerful ways to promote thinking about Teacher Learning. The concepts of BBBB as a teacher were developed initially as part of curriculum renewal activities in the Faculty of Education of the Nelson Mandela University in 2013. Originally, the concepts were termed Transitioning, Becoming, Being, and Belonging as an acknowledgement of the early childhood sources that stimulated thinking and conceptualisation (Australian Government Department of Education \& Relations, 2009). This early childhood curriculum resource used the concepts of Belonging, Being, and Becoming to underpin early-years programmes. The Faculty of Education curriculum developers rearranged these early-years concepts to show stages of envisaged pre-service Teacher Learning as Becoming, Being, and Belonging. Young children transition from pre- 
school to Grade 1. Similarly, first-year students transition to new stages of learning (i.e. from Grade 12 to higher education). "Transitioning" was, thus, included as the first stage of student Teacher Learning in order to show the movement from school learner to student teacher. Later, in the interests of onomatopoeia, as well as certain pedagogical considerations, the term "Transitioning" was replaced with "Bridging." By 2014, the concepts of BBBB were used by the Faculty of Education curriculum developers to refer to the integrated learning components of the first, second, third, and fourth year of the BEd curriculum. Sathorar and Geduld (2018) offered a perspective on the use of BBBB to develop a new and emancipatory teacher education qualification.

Achieving a state of teacherness is more than progressing successfully through several years of study. It includes personal change in relation to self and others and understanding and growth within a community of practice (Williams et al., 2012). In this study BBBB are used as identity shifting devices and prompts for engaging with the quest to become an agent of social change within an educational environment. Trafford and Leshem (2008) explored the notion of what they called doctorateness. Their approach can be used to understand the idea of teacherness since the former "combines both 'doing' and 'achieving' a doctorate" (p. 36). The doctoral candidate is required to demonstrate doctorateness. Trafford and Leshem further indicated various aspects to be considered when one is determining doctorateness, namely, "establishing conceptual links between findings, synthesising evidence into conceptual conclusions, critiquing the research process, advancing contributions to knowledge" (p. 19). Individual teachers are able to reflect on and enact progress towards teacherness by engaging with a range of sources within and outside the educational system.

The aim of this enquiry is to consider ways in which student teachers can move beyond the boundaries of their school-based learning experiences to learn from and with other beginner teachers, prompted by various visual activities. The uncertain spaces encountered during teaching practice are investigated. By participating in creative activities, student teachers are able to share aspects of their learning and engage with the experiences of other student teachers. The mutual vulnerability and dependence of students and staff, in turn, affect the environment wherein their interactions occur (Fraser et al., 2003). Both students and staff have responsibility regarding progress on a journey towards teacherness. In this paper, I use visual and creative enactments to understand this risky, but promising, space.

\section{Conceptual framework}

The conceptual lens used in this study brings together understandings of the space and the way in which teacherness could be developed. The environment of learning to teach is envisioned as one of mutual vulnerability and dependence. This space is initiated through agentive creativity. 


\section{Mutual vulnerability and dependence}

Keet et al. (2009) used the concept of mutual vulnerability to address the reality of educational inequalities, calling for an educational environment of "shared moderation, learning and critical self-reflection to create the space for renewed and meaningful teaching and learning" (p. 109). Mutual vulnerability includes recognition of and care for the "identities, histories and experiences of students and teachers" (p. 111). Mutual vulnerability can be paired with the notion of mutual dependence. Fraser et al. (2003) referred to the link between human beings and the world as being both mutually vulnerable and mutually dependent. These authors maintained that the environment can be impacted by humans, and that the environment has an impact on its inhabitants. The ideas of mutual vulnerability and mutual dependence can also be employed in relation to Teacher Learning. For example, staff can abdicate power and authority and adopt a different learning stance in their engagement with students (Keet et al., 2009). As these scholars have pointed out, this interrelationship of vulnerability can bring about reconciliation and has benefits for both students and staff.

Dependence, in the context of teacher preparation, can nurture the reliance between and among students and staff. As parts of a learning-to-teach community that includes student teachers, university staff, school mentors, Department of Basic Education officials, and others, students and higher education staff members can either assist or hamper each other. Similarly, in the natural world, plants and animals have a dependent relationship within a living community or ecosystem. The survival of the community is impacted by the interaction and reliance of members of the ecosystem on each other (Potts et al., 2010). A learning-toteach ecosystem can be understood as a community of interacting elements that is able to nurture growth towards teacherness. It is a system of interconnected individuals, formed by the interaction of a group of educational role-players, within a particular environment. The role-players (i.e. elements of the ecosystem) considered in this study include preservice student teachers and university staff members.

\section{Agentive creativity}

Individuals have the capacity for collaborative engagement and agentive creativity as Stetsenko (2018) has reminded us. While creativity can be affirming and generative, it also offers the possibility of opposition and critique and of moving beyond the status quo (Stetsenko, 2019). The collaborative nature of creativity is recognised and human beings are involved in "co-creating and co-authoring the world" (Stetsenko, 2018, p. 44). The world or reality that is co-constructed by students and staff is comprised of alternatives, challenging options, uncertainty, and fear. However, there is also space for determined and optimistic action (Stetsenko, 2018). Visual methodologies offer the possibility of an innovative exploration of experiences (Mannay et al., 2017), seeing in new ways, and moving towards transformed practice (Mitchell et al., 2015) as the teacher learning space is traversed. 


\section{Methodology and methods}

De Lange et al. (2015) have explained how visual methodologies can be used to prompt transformation. They showed us how to elicit "portraits of change" that can be used to produce an adjustment in thinking and prompt agency and action (p. 16). Participatory research has the potential to effect change for and with research participants (Pain \& Francis, 2003). The learning journey of students, as beginner teachers, is explored using a range of visual techniques in this enquiry. Photo-voice is used to elicit data from senior students regarding their experiences in schools. An exhibition of this visual work initiates a conversation and involves a learning-to-teach community in an image-based interaction about Teacher Learning in diverse schooling contexts. Collages provide a means for staff members to contribute perspectives and join the conversation on Teacher Learning. Insights prompted by the photo-voice exhibition and collage pieces are then used by first-year students to reflect on their school-based experiences. They communicate their emerging understandings of learning to teach by means of drawings. In the following section, I provide details regarding the creative opportunities used to negotiate and move across the learning-to-teach terrain.

\section{Photo-voice: Seeing, thinking and wondering about being a beginning teacher}

Third-year BEd student teachers had the opportunity to reflect on their experiences in schools at the start of the academic year. A prompt, "See, Think, Wonder (STW)" (a thinking strategy devised by the Harvard Project Zero Visible Thinking team) as documented by Ritchhart (2002), was used to generate images and accompanying written pieces. As part of the formal reflection activities in a BEd 3 school-based learning module, student teachers were guided to provide a visual image that depicted either opportunity, hope, or challenge. Thereafter, they had to use STW to engage with the image, A total of 319 students completed this reflection activity. Responses were assessed and students received feedback on their work. Information in the module guidelines indicated that aspects of student work could be used for research purposes in order to improve the delivery of the module. Students had the opportunity to refuse to have their work included. The ethical procedures of the university were followed in terms of using student populations as research participants. ${ }^{1}$ For the purposes of this research undertaking, only photographs created by student teachers were considered. Found photographs, pictures, and drawings by third-year students were not included. In addition to the standard ethics procedures of the university, the ethics of dissemination (see Khoja et al., 2015) were considered. Students thus had the opportunity to withhold permission to have their work exhibited.

Following Mitchell (2015), both the interests of any subjects in the images and those of the creators were taken into consideration. A random selection of 25 photo-voice pieces was initially made. The aim was to have 12 to 15 pieces for the exhibition. Student volunteers made selections using specified criteria as guidelines. The aim of the exhibition was to initiate visual interaction between student year groups and other members of the Teacher Learning community. Ultimately, 12 photographs and their accompanying texts were

The ethics number allocated by the university was H19-EDU-ERE-001. 
included in the exhibition that took place in a lunchtime slot during the university's Teaching and Learning week. The university community and visitors were invited to view the students' work.

After we displayed the work in an outdoor communal area, the exhibition was relocated to the Faculty of Education Resource Centre. There was an opportunity for those viewing the exhibition, in both venues, to respond to the exhibition. Another Harvard Project Zero visual activity was used to elicit such responses, namely the Connect, Extend, Challenge (CEC) artful thinking strategy (Ritchhart \& Perkins, 2008). This strategy allowed viewers to speak back to the exhibition (see Mitchell, 2015). The prompts, available in handout format, were: How is the exhibition connected to something you know about? What new ideas or impressions do you have that extended your thinking in new directions? What is challenging or confusing? What do you wonder about?

Audience responses were collected and displayed in a file in the Resource Centre. Visitors to the Resource Centre had the opportunity to view the STW exhibition and write back using the CEC prompt mentioned earlier. Alternatively, exhibition visitors could respond in what Bean and Elbow (2009) termed a freewriting format. First-year students were invited to view the exhibition and written responses before their first school-based learning opportunity at the beginning of their second semester. The exhibition remained up for the duration of the semester and was a reference point for the drawing activity required of the first-year students.

\section{Collage work: Investigating beginning teacher identities}

The Institution's revised BEd curriculum uses the concepts BBBB to designate and describe school-based learning opportunities in each of the four years of study. These tags are also considered as markers of teacher identity along a continuum of Teacher Learning. Hence, a collage process was designed by the research team to establish an understanding of what these concepts could mean as signifiers of a learning-to-teach process. Three staff research team members (two academics and a school-based learning administrator) collaborated in the collage process. The crafting and engaging with collage pieces allowed entry into the learning-to-teach conversation. The aim of the BBBB collage activity was to offer a visual and creative perspective regarding what the stages of Teacher Learning might represent. The collage work included photo elicitation, crafting four collage pieces, and what we have come to call Close Viewing to highlight emerging meanings.

The collage work included both images and text. The primary images were photographs. Copyright-free images came from https://www.pexels.com/ using the search phrases bridging, becoming, being, belonging, teaching, and learning. Students were seen as becoming members of a community of practice (see Sathorar \& Geduld, 2018). Thus, the additional search items of periphery and centre, following Lave and Wenger (1991) were used to show movement in a Teacher Learning process towards being centred or belonging. Staff members collaborated to select images for each collage piece. The plan was to develop a collage to represent each of the concepts of Bridging, Becoming, Being, and Belonging, as described in the BEd curriculum and faculty prospectus. The technical descriptor from the 
prospectus and a visual expansion of the concept were used to help students and staff to think more deeply and creatively about the envisaged Teacher Learning process. The collage pieces were crafted using elicited photographs, curriculum documents, images of the growth of teachers from apprentices to experts, and visualisations of the movement from periphery to centre. In line with Butler-Kisber (2008), art elements such as colour, shape, line, positioning, and texture were also considered and employed.

The collage work was shared with first-year students after they returned from their visits to schools. This offered students an opportunity to reflect on the conceptualisation of schoolbased learning within the BEd programme. Students were able to place themselves and their recent experiences in schools within a visually depicted space of Teacher Learning. This visual placement stimulated the first-year drawing activity. After viewing the collages and engaging with the exhibition of peer photo-voice work, students were invited to show, through drawing, who or where they were as teachers.

\section{Drawing: Sketching who or where you are as a beginning teacher}

BEd 1 students had the opportunity to respond to the exhibition of senior student work by participating in the CEC activity, or by contributing freewriting responses. Additionally, a selected group of first-year students participated in a drawing activity to depict aspects of their learning-to-teach experience. BEd Intermediate Phase (IP) students were invited to participate in a drawing process. This selection was based on convenience sampling since the research team worked in the BEd IP programme. Of the 164 IP first-year students, 144 participated in the drawing activity.

Students were invited to create black and white drawings showing either who they were or where they saw themselves as beginner teachers. They were asked to supply accompanying texts of at least 50 words as an initial interpretation of their drawings. It was important to capture aspects of each participant's work and weave these into a story to communicate back to them. This gave the group who generated the drawings, and a broader audience, an understanding of the emerging insights of students at the beginning of their learning-to-teach journey. A key idea from each drawing was formulated. These ideas were woven into a word tapestry and shared with the creators of the drawings to ensure that each drawing was adequately represented. Participants were given the opportunity to suggest alternative written representations of their drawings. The word tapestry could be understood as a collage of written texts. The fragments representing first year work were woven together to make a summative picture of the outcomes of the visual participatory process.

\section{Findings}

A creative, participatory process was used to surface views and visions of learning to teach. Senior students provided glimpses of their school-based learning experiences in photo-voice reflections. These were shared in an exhibition in order to initiate visual communication in the Faculty of Education as a teacher-learning environment. Staff members joined the visual conversation by creating and/or scrutinising a set of collages that interrogated the 
underpinning ideas of the teacher education curriculum in relation to BBBB. First year students had the opportunity to view the work of fellow students and staff as a precursor to their school-based learning opportunity. On their return to campus, they communicated their ideas about learning to teach through drawings and accompanying texts. In order to weave a story about the insights of first year students as beginner teachers, a word tapestry was crafted. Key ideas from this tapestry were distilled and a learning-to-teach collage was created. Two sets of insights emerged from the webs and threads of visual work. The first related to disruption and challenge and the second to collaboration and coalescing.

\section{Challenging boundaries and seeing differently}

Opportunities and challenges were captured, and a sense of hope depicted in many of the evocative images and texts produced by third year students (see Figure 1).

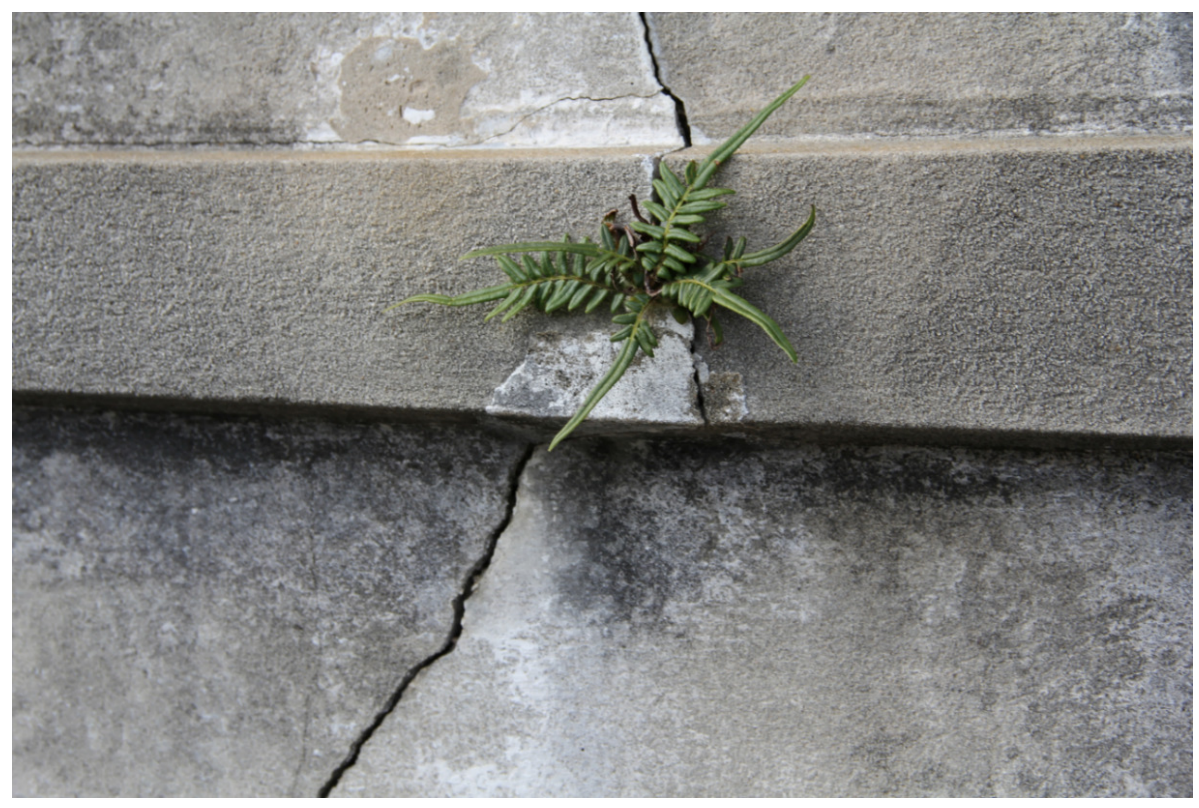

Figure 1: Hope in the Cracks of Life, by Alulutho Qundani

This picture shows a plant growing in a cemented, cracked wall. The image depicts hope.

In this picture, I see children who will come to my classroom with many problems.

I think of all the ways I will provide a great, conducive learning space that will help them focus on their future, rather than the problems and fears they have.

I wonder if I will be able to put the above into action.

As previously noted, students, staff, and the community could engage with the STW photovoice work exhibition. The STW visible thinking strategy (Ritchhart \& Perkins, 2008) offered a means of collective viewing and pondering on the learning-to-teach process. Since audience members could respond using the artful thinking routine CEC, they prompted others to see differently (which is a key affordance of visual methodologies). A participant's 
photograph "captures the world" and affords "subsequent knowledge production" (Glawet al., 2017, p. 1). Responses to Hope in the Cracks of Life (Figure 1) included:

Wow-strange to think that children with problems can make someone feel hopeful . . . She seems confident that she can make a difference-a good idea to teach children to be future focussed. (CEC: 5 )

The collage process undertaken by staff added further voices to the learning-to-teach conversation. Once the collages were ready, a Close Viewing process was undertaken by three research team members. Similar to Close Reading used in literature studies, participants looked with focussed attention at each collage and used sticky notes to comment on meanings arising from each piece. Although several important understandings emerged from the Close Viewing activity, only the idea of not belonging is dealt with in this paper. The official descriptors for school-based learning modules emphasise a movement towards belonging: Year 1: Starting Out as a Beginning Teacher; Year 2: Becoming a Student Teacher; Year 3: Being a Student Teacher; Year 4: Belonging to a Community of Practice. The Close Viewing process disrupted the fluid progression conceptualised in BBBB and showed that in working towards Teacher Learning, episodes of not belonging could be useful. Discontinuity of student teacher placement experiences offers important learning opportunities as Mesker et al. (2018) have pointed out. Discussion during the Close Viewing analysis process confirmed that most students preferred familiar settings, often similar to those of the schools they attended, which resonated with views of teacher socialisation during their school years (Wall, 2016). Helping aspirant teachers understand the value of boundary crossing and not belonging surfaced during the collage work engagement. Boundary crossing is acknowledged as having significant potential for learning and the development of identity and practice (Akkerman \& Bakker, 2011). Although boundary transitions can be uncomfortable, they can have value and can prompt understanding and learning, as evidenced in Figure 2.

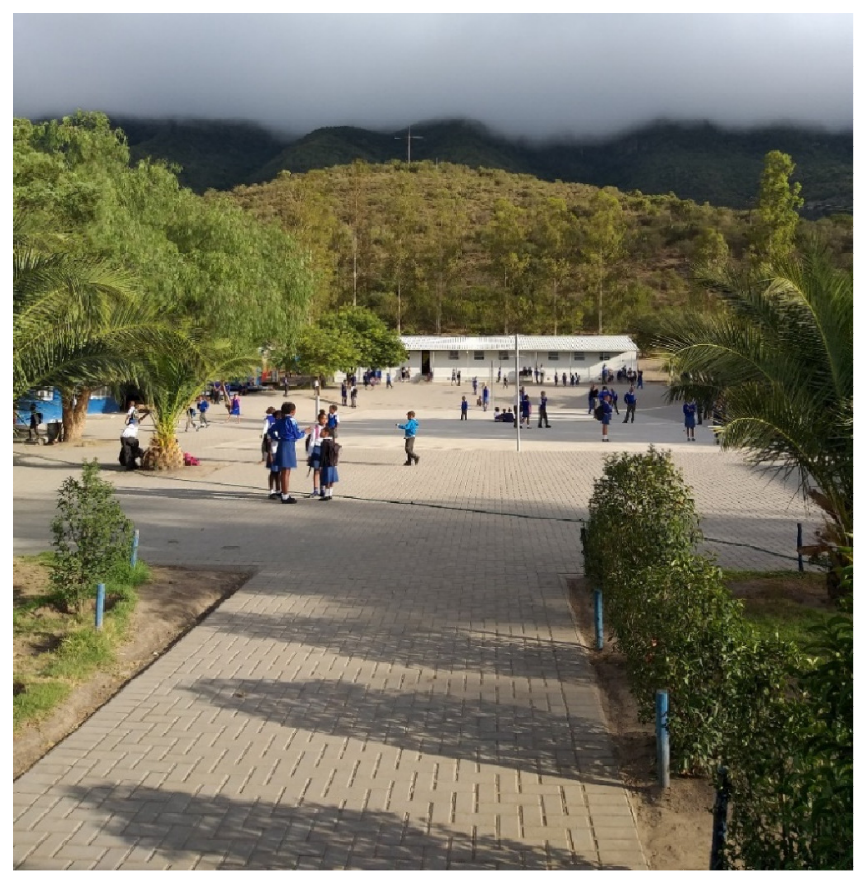

Figure 2: Challenge, Agency, and Happiness, by Anlou Botha 
I started my journey for School-Based Learning in my 3rd year, at a new school, with a new environment and completely different learners. The first thing to draw my attention was the challenges the school is facing. There are so many different challenges on various levels. One of the major challenges the school encounters is a lack of resources. This affects the learners' ability to reach their full potential.

Poverty impacts hard on the school and this makes learning difficult. Children sometimes only eat once a day and that is the food the school provides. As a result, learners struggle to keep their concentration on their schoolwork.

I see all the challenges the school has to face and all the effort the teachers invest. I think the staff at this school really make a difference in the lives of the children. They try to keep the learners motivated and teach them as best they can with the resources available.

After observing this, I am left wondering how long the school can go on like this and remain a functional school. The question remains: What will happen to the children? Despite the circumstances, the children seem content. The picture above was taken before school as the learners arrive at school and play together. They seem more than happy with their school.

Through this piece, it seems that Anlou had the courage to move across a boundary towards the less familiar. She indicates a placement for school-based learning "at a new school, with a new environment and completely different learners." Although challenges are obvious, Anlou resists a deficit positioning and alerts her audience to the efforts of the teachers who teach, "as best they can with the resources available." The audience is left wondering about the future of the children and the apparent contradiction of a challenging environment and happy children. The traversing of economic and social boundaries by hard-working teachers may leave a sense of puzzled admiration in exhibition participants. Mesker et al. (2018) illuminated the idea of a boundary as being "a metaphor for an experience of discontinuity wherein a socio-cultural difference is perceived as a challenge or obstacle in action or interaction" (p. 1). The clear challenges and apparent contradictions in the school circumstances that Anlou highlights have the potential to prompt consideration and conversation within a learning-to-teach community.

The quiet allure of the image in Figure 2 captures the attention of viewers while the thoughtprovoking text suggests nuances in learning to teach that may linger long after the viewer has left the exhibition. The example of boundary crossing and possible not belonging are clear threads of the learning-to-teach conversation playing out between the exhibited photo-voice work and the collage pieces. First-year student teachers had the opportunity to discern these and other threads as they viewed the exhibition and collage works. They were encouraged to reflect on their own school-based learning experiences and find similarities and dissonances between their view of learning to teach and that of others. This contemplation and consideration prepared students for the drawing activity. For this activity, black and white drawings were created in response to the prompt, "Who or where are you as a beginning 
teacher?" The first-year students' drawings and accompanying texts provided another glimpse into the understandings of Teacher Learning. Their visual communication was informed by the images of senior students and staff and their own experiences. The drawings showed both the difficulties and possibilities of the learning to teach terrain.

\section{Collaborative sense making and situating}

First year students drew pictures and wrote accompanying texts to assist viewers to interpret their drawings. In order to make sense of the visual conversation that was emerging, a selection of text was extracted from each written piece. As a thread linked to each drawing was extracted, patterns began to form.

Several focal areas appeared: Puzzles and Pondering, Seeing and Gaining Insight, Growing and Making Progress, Doubting and Hanging in, Steps and Stairways, and Contributing and Becoming a Teacher. After ensuring that participants' work was adequately represented by an appropriate text-thread, each focal area was allocated a colour.

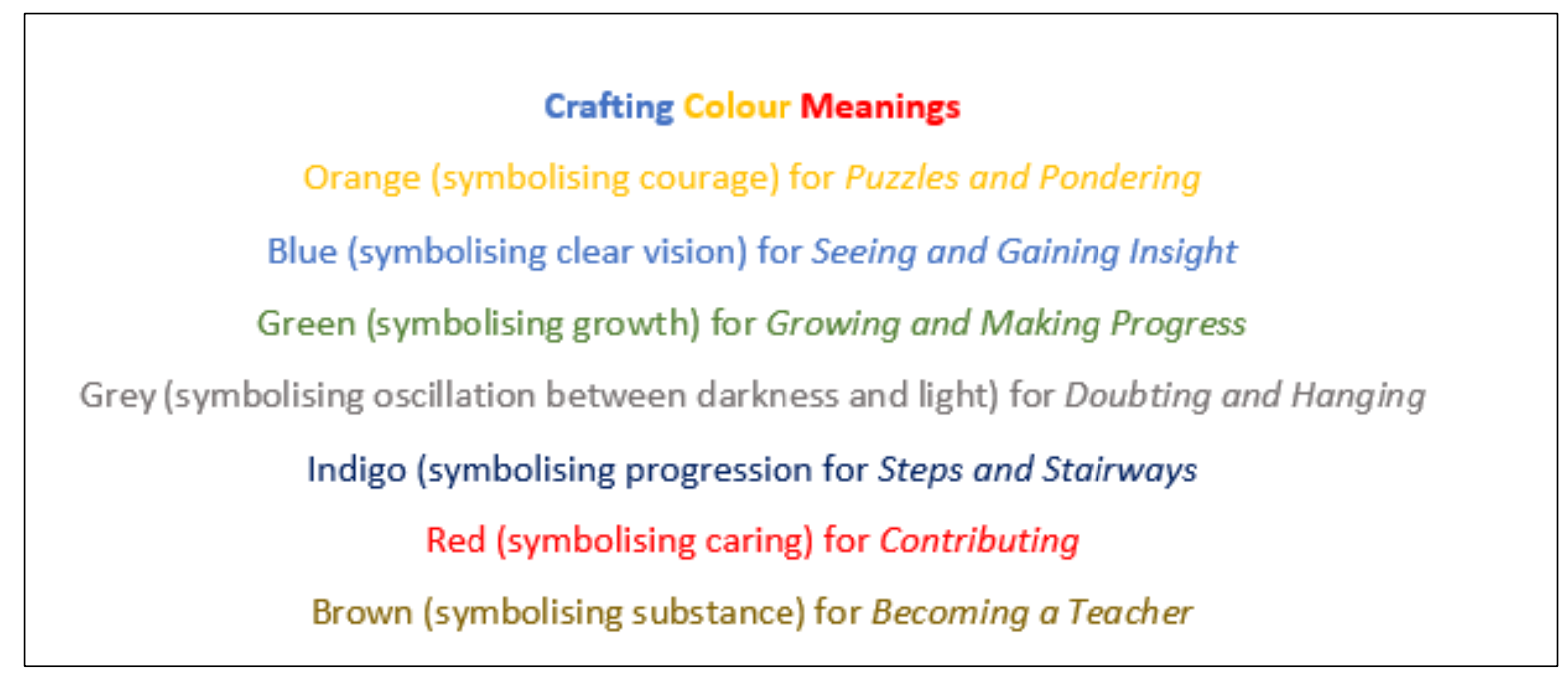

Figure 3: Colour clues

An image depicting the intricate and sometimes messy work of learning to teach was elicited from a copyright free visual source, pixabay.com. The metaphor of a tapestry was chosen to show how strands of understanding were woven together. Shades of each colour were used to colour the threads in each area (Figure 3). In the case of Puzzles and Pondering, light orange was used to indicate being unsure and unsafe (a-f). A darker orange shade was used to indicate more confidence (g-k). A bold orange (l) was used to indicate feeling stronger and dealing with apprehension. 


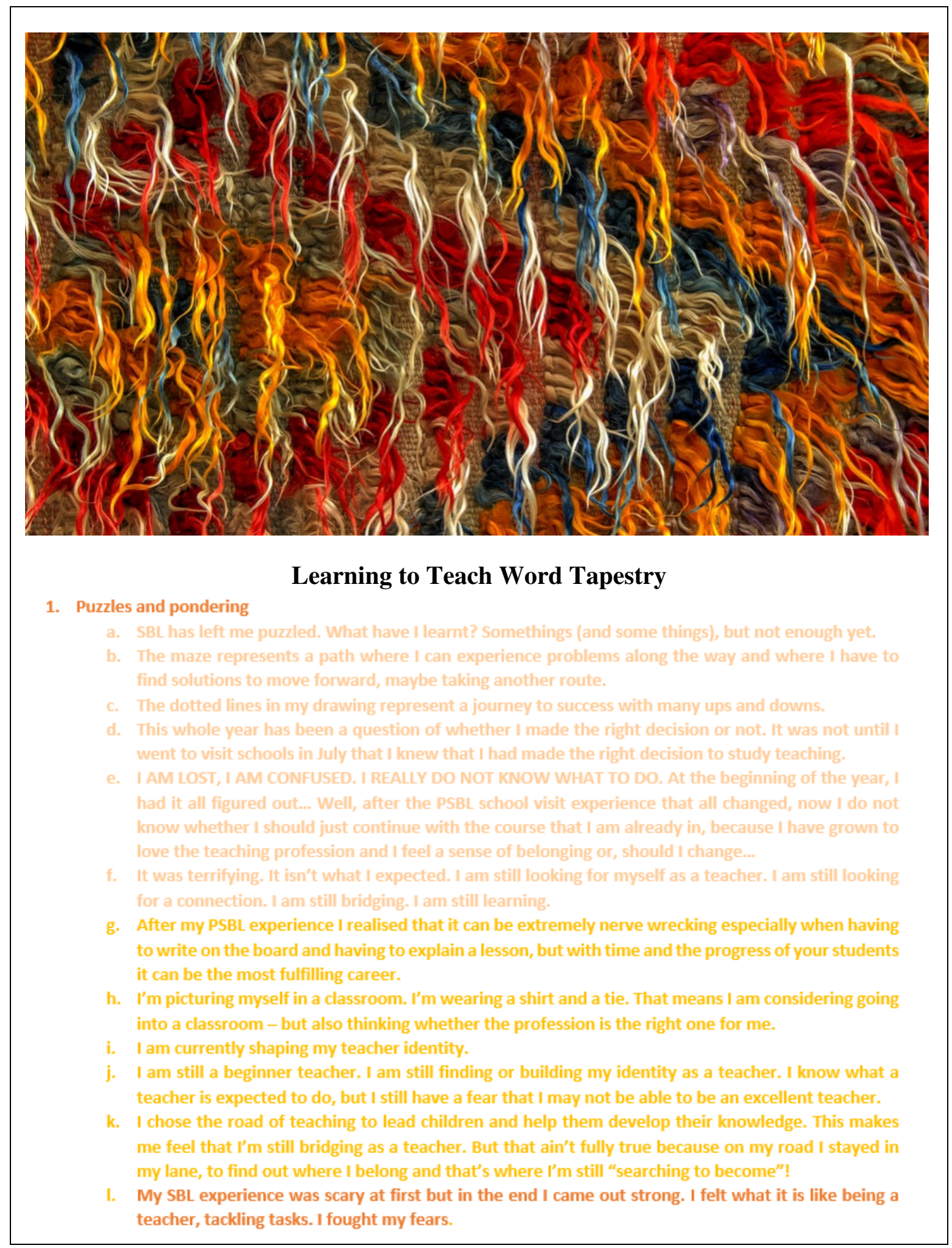

Figure 4: Extract from word tapestry

The word tapestry served as a visual artefact representing and honouring the journey of each participant. A collective visual representation of students' drawings and their thinking about their learning-to-teach trajectory had, thus, been woven with words. After scrutinising and sharing the tapestry with students, it became obvious that the seven focal points had some overlap and could be shaped into five distinct areas of emphasis: Puzzles and Pondering, 
Seeing and Gaining Insight, Growing and Making Progress, Doubting or Hanging in, and Contributing and Becoming a Teacher. In order to sharpen the understanding of what was emerging from the tapestry, drawings that resonated with each area of emphasis were selected from the first-year submissions and used to create a collage.

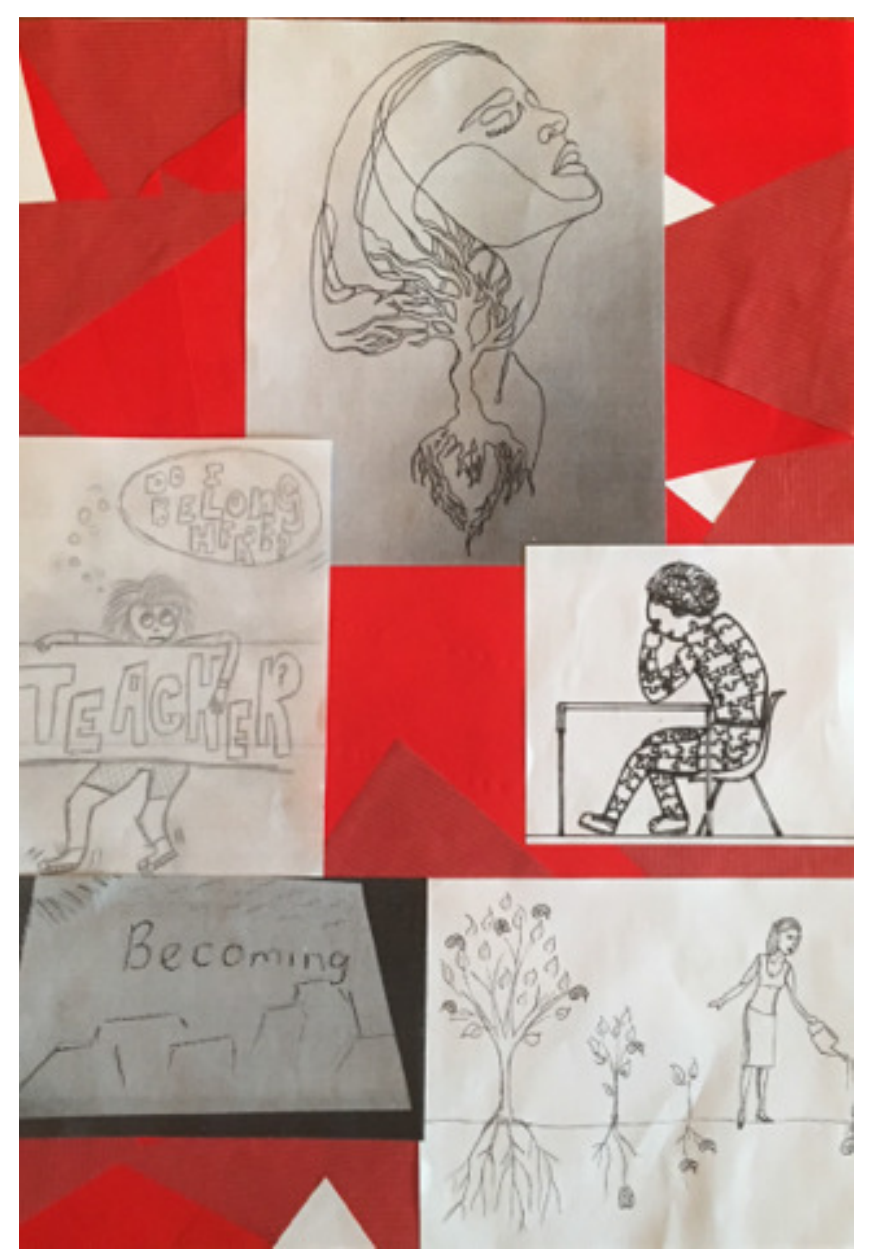

Figure 5: Picturing Learning to Teach

The areas of emphasis offer samples of students' views regarding embarking on the learningto-teach journey. The written and visual texts show their emerging understandings of teacherness.

Puzzles and Pondering shows beginner teachers as hesitant and confused.

SBL has left me puzzled. What have I learnt? Somethings (and some things), but not enough yet. (1a)

\section{AM LOST, I AM CONFUSED. I REALLY DO NOT KNOW WHAT TO DO. At} the beginning of the year, I had it all figured out . . . now I do not know whether I should just continue with the course that I am already in, because I have grown to love the teaching profession and I feel a sense of belonging or, should I change . . . (1e) 
Despite students' uncertainty, responses hint at their willingness to continue on the learningto-teach journey to discover whether or not the profession suits them and what their identity might be.

I'm picturing myself in a classroom. I'm wearing a shirt and a tie. That means I am considering going into a classroom but also thinking whether the profession is the right one for me. (1h)

My SBL experience was scary at first but in the end, I came out strong. I felt what it is like being a teacher, tackling tasks. I fought my fears. (11)

Students' readiness to accept the discomfort of not fully knowing suggests bravery and resolve, as first-year students begin their expedition towards teacherness.

Seeing and Gaining Insight depicts student teachers as developing insights as beginner teachers. It also captures understandings of how student teachers view learners during their school visits.

My SBL experience completely opened my eyes to the challenges and various types of learners in the community. It encouraged me to become more open minded and take a step back in order to allow myself to fully develop into a future teacher. (2i)

Looking at my sketch, we can see it is a thriving ecosystem. (2p)

Teachers are required to see and welcome learners, and what they bring to the classroom. When there is a mutual valuing of the capabilities of teachers and learners, a productive learning community can exist.

Growing and Making Progress reveals that beginner teachers are aware that they have initiated a process. There is a strong sense of beginning, with several stages still ahead. Two metaphors dominated the students' drawings, namely a plant growing and a journey.

I have grown as a beginner teacher and I am slowly allowing positive things into my life-things that will change me for the better. (3k)

I see myself in the picture of a growing plant in early stages just after appearing above the ground level. I am still delicate, and my growth and direction is much depending on environment factors. (3o)

My journey of becoming a teacher-I compare it with natural beings, the rising sun between the mountains shows where I am at now. The river flowing, feeding the green grass and trees, represents my mind gathering all the knowledge, skills and experiences I have had thus far. This whole drawing shows what I have learnt and with the SBL experience I have I feel like the sun is rising in my journey and it's a wonderful and beautiful journey. (3x) 
Teachers with a well-developed sense of awareness are able to attend to their own growth and nurture the growth of their learners. As part of enacting a curriculum, teachers can make space for learners to be present, rather than excluded, to find their place and grow.

Doubting or Hanging in reveals students' notions of their increasing euphoria about learning to teach being interrupted. In this part of the tapestry, the eye moves over the alluring colours of orange, blue, and green, and is then halted by the sombre grey threads that tell of uncertainties and misgivings.

Can I take on all the roles? ... Do I really belong in this profession? (4a)

The process of becoming a teacher can be tiring at times. My SBL experience reminded me why I am studying education. It's like children have a direct string attached to my heart and when I become despondent or overwhelmed, it's my future learners that pull me through. $(4 \mathrm{~d})$

I did not know what to expect on my first day and this made me a bit scared to be honest. The classroom environment was very calm, and I think this helped me to calm down also. (4f)

Students' yearning for a more comfortable place is evident as each grey thread is considered. Anxiety shifts towards a calmer, but still hesitant, realisation that teaching might be a good career choice and could even be enjoyable. A safe and invigorating environment is an essential requirement for creating a place for learning to flourish. Interaction of elements in the learning ecosystem leads to sustainability and balance.

Contributing and Becoming a Teacher provides a final glimpse into students' perceptions of promises and possibilities.

I am imagining myself in a class playing an important role, inspiring, motivating, encouraging, and shaping. (5a)

The relationship I built with those kids made me to realise that my community needs new Vibrant Teachers. I felt ready to be a teacher and serve in my community. (5b)

I am beginning to think that this is for me, and I will do whatever it takes to equip myself with relevant knowledge to build up myself to bring the change I want to see in my country and the world at large. $(5 q)$

The contributions of first-year students evidence efforts to understand and make meaning of what it is to be a teacher in the complex South African school landscape. This learning to teach terrain is not neutral or necessarily safe. As the tapestry is viewed and threads are read, it is clear that some first year student teachers are still uncomfortable. They have not crossed a bridge towards teacherness. Others evidence becoming familiar with and situated in their learning-to-teach journey. Their sense of themselves and their place in a teaching environment is emerging. 


\section{Discussion}

Collectively, members of the learning-to-teach community (i.e. first-year students, senior students, and faculty staff members) could engage with and shape the visions of what it means to become a teacher. Learning to teach is a complex but valuable process. Weft and warp threads together make a tapestry (Crane et al., 2017). The presented student contributions can be considered the weft threads. The warp strands could represent the staff engaging with the student teachers. Together, these weft and warp strands are able to create an artefact of Teacher Learning with aesthetic appeal and profound social promise.

The resultant tapestry makes a strong visual statement. It has the power to promote thinking and spur action. A "tapestry of human potential" appears from the interaction and interdependence of the weft and warp elements (Wood, 1995, p. 44). The sturdy and sustainable woven fabric is possible only because of the connection between these threaded elements. This speaks to the mutual vulnerability and dependence of students and staff (see Fraser et al., 2003).

Individual weft and warp threads are relatively weak and vulnerable. However, when woven into a tapestry, their dependence becomes their strength and contributes to the aesthetic quality and durability of the tapestry. The interconnectedness of threads is similar to the interconnectedness within a balanced ecosystem or community. Careful and considered interactions of a Teacher Learning community can result in states of teacherness that have the beauty of a carefully woven tapestry and the balance of a sustainable ecosystem.

Visual participatory activities gave rise to a conversation about the learning-to-teach journey. Students and staff met each other and collaborated in what Roux and Becker (2016) thought of as a dialogic engagement. Interested, respectful communication characterises this engagement as Lane and Kent (2018) have noted. For this dialogic interaction to take place, there must be "the acknowledgement of situated selves, and the ontological need for, and right to, voice" (Roux \& Becker, 2016, p. 131). This study demonstrates that participant voice and views are possible when visual participatory methodologies are employed. Students and staff had the opportunities to use visual and creative processes to position and situate themselves in terms of their understandings of teacherness and consider the way forward on a learning-to-teach journey. The artful portrayals were at times challenging and disruptive. The boundaries described elsewhere by Akkerman and Bakker (2011) had to be crossed and identities shifted as Beauchamp and Thomas (2011) noted in a different context. This discomfort enabled the forward movement and transitioning that Stetsenko (2019) has commented on. In other instances, the visual activity was more harmonious, and understandings coalesced. Collaborative engagement prepared the ground for the agentive creativity advocated by Stetsenko (2018). Students and staff co-created and co-authored the envisaged teaching world. Visual activities succeeded in prompting re-viewing taken-forgranted understandings to which Mannay (2010) has referred elsewhere, and familiar notions of teaching could be reframed. 


\section{Conclusion}

Visual approaches enable non-linear thinking and can shift the power balance of knowledge creation. As a result of the use of a range of visual participatory activities, both students and staff emerged as knowers regarding teacherness and learning to teach. Agentic creativity enabled the challenging of boundaries and seeing differently. Subtle shades of meaning emerged when the learning-to-teach journey was considered. The belief in an easy progression through stages of teacher preparation was problematized in the visual responses of students.

The visual engagement of students and staff demonstrated that visual methodologies can be used as tools for collaborative meaning making. The familiar and taken-for-granted can be reviewed and borders and boundaries traversed. Weaving creative activities with visually based dialogic engagement holds transformative promise for teacher learning. Uncertain spaces can be bridged when students and staff form a learning ecosystem and are willing to be mutually vulnerable and dependent. Within this environment, there is a space for openness, respect, hope, and courage.

\section{References}

Akkerman, S. F., \& Bakker, A. (2011). Boundary crossing and boundary objects. Review of Educational Research, 81(2), 132-169.

Australian Government Department of Education, E., \& Relations, W. (2009). Belonging, being and becoming: The early years learning framework (EYLF) for Australia. Commonwealth of Australia.

Ayers, W. (2015). To teach: The journey of a teacher. Teachers College Press.

Baden, M. S., \& Wimpenny, K. (2014). A practical guide to arts-related research. Springer.

Bean, J., \& Elbow, P. (2009). Freewriting and free speech: A pragmatic perspective. Journal of Teaching Writing, 25(1), 1-23.

Beauchamp, C., \& Thomas, L. (2011). New teachers' identity shifts at the boundary of teacher education and initial practice. International Journal of Educational Research, 50(1), 6-13.

Butler-Kisber, L. (2008). Collage as inquiry. In J. G. Knowles \& A. 1. Cole (Eds.), Handbook of the arts in qualitative research (pp. 265-276). SAGE.

Conway, P. F., \& Clark, C. M. (2003). The journey inward and outward: A re-examination of Fuller's concerns-based model of teacher development. Teaching and Teacher Education, 19(5), 465-482. 
Crane, R., Brewer, J., Feldman, C., Kabat-Zinn, J., Santorelli, S., Williams, J., \& Kuyken, W. (2017). What defines mindfulness-based programs? The warp and the weft. Psychological Medicine, 47(6), 990-999.

De Lange, N. (2008). Visual participatory approaches to HIV and AIDS research as intervention in a rural community setting. Journal of Psychology in Africa, 18(1), $179-185$.

De Lange, N., Moletsane, R., \& Mitchell, C. (2015). Seeing how it works: A visual essay about critical and transformative research in education. Perspectives in Education, $33(4), 151-176$.

Feiman-Nemser, S. (2001, December). From preparation to practice: Designing a continuum to strengthen and sustain teaching. Teachers College Record.

Fraser, E. D., Mabee, W., \& Slaymaker, O. (2003). Mutual vulnerability, mutual dependence: The reflexive relation between human society and the environment. Global Environmental Change, 13(2), 137-144.

Glaw, X., Inder, K., Kable, A., \& Hazelton, M. (2017). Visual methodologies in qualitative research: Autophotography and photo elicitation applied to mental health research. International Journal of Qualitative Methods, 16(1), https://doi.org/10/1177/16094069177448215.

Huebner, T. (2009). The continuum of teacher learning. Educational Leadership, 66(5), 8891.

Keet, A., Zinn, D., \& Proteus, K. (2009). Mutual vulnerability: A key principle in a humanising pedagogy in post-conflict societies. Perspectives in Education, 27(2), 109-119.

Khoja, N., Makramalla, M., Khan, F., Burkholder, C., \& Abdou, E. (2015). Why study power in digital spaces anyway? Considering power and participatory visual methods. Perspectives in Education, 33(4), 6-22.

Lane, A., \& Kent, M. L. (2018). Dialogic engagement. In K. Johnston \& m. Taylor (Eds.), The handbook of communication engagement (pp. 61-72). Wiley Blackwell

Lave, J., \& Wenger, E. (1991). Situated learning: Legitimate peripheral participation. Cambridge University Press.

Mannay, D. (2010). Making the familiar strange: Can visual research methods render the familiar setting more perceptible? Qualitative Research, 10(1), 91-111.

Mannay, D. (2014). Visual methodologies: Participatory potential, practicalities, defamiliarisation and dissemination. SAGE. 
Mannay, D., Staples, E., \& Edwards, V. (2017). Visual methodologies, and psychoanalysis: Employing creative participatory techniques to explore the educational experiences of mature students and children in care. Visual Studies, 32(4), 345-358.

Mesker, P., Wassink, H., Akkerman, S., \& Bakker, C. (2018). Student teacher's boundary experiences during an international teaching internship. Cogent Education, 5(1). https://doi.org/10/1080/2331186X. 2018.1498577.

Mitchell, C. (2015). Looking at showing: On the politics and pedagogy of exhibiting in community-based research and work with policy makers. Educational Research for Social Change, 4(2), 48-60.

Mitchell, C., De Lange, N., \& Moletsane, R. (2017). Participatory visual methodologies: Social change, community and policy. SAGE.

Mitchell, C., Moletsane, R., \& De Lange, N. (2015). Seeing how it works: A visual essay about critical and transformative research in education. Perspectives in Education, $33(4), 151-176$.

Pain, R., \& Francis, P. (2003). Reflections on participatory research. Area, 35(1), 46-54.

Potts, S. G., Biesmeijer, J. C., Kremen, C., Neumann, P., Schweiger, O., \& Kunin, W. E. (2010). Global pollinator declines: Trends, impacts and drivers. Trends in Ecology \& Evolution, 25(6), 345-353.

Rauduvaita, A., Lasauskiene, J., \& Barkauskaite, M. (2015). Experience in teaching practice of pre-service teachers: Analysis of written reflections. Procedia-Social and Behavioral Sciences, 191, 1048-1053.

Ritchhart, R. (2002). Intellectual character: What it is, why it matters, and how to get it. John Wiley \& Sons.

Ritchhart, R., \& Perkins, D. (2008). Making thinking visible. Educational leadership, 65(5), 57-61.

Roux, C., \& Becker, A. (2016). Humanising higher education in South Africa through dialogue as praxis. Educational Research for Social Change, 5(1), 131-143.

Sathorar, H., \& Geduld, D. (2018). Towards decolonising teacher education: Reimagining the relationship between theory and praxis. South African Journal of Education, 38(4), 112.

Stetsenko, A. (2018). Agentive creativity in all of us: An egalitarian perspective from a transformative activist stance. In M. C. Connery, V. John-Steiner \& A. MarjanovicShane (Eds.), Vygotsky and creativity: A cultural-historical approach to play, meaning making, and the arts (2nd ed.). Peter Lang. 
Stetsenko, A. (2019). Creativity as dissent and resistance: Transformative approach premised on social justice agenda. In I. Lebuda \& V. Glaveanu (Eds.), The Palgrave handbook of social creativity research (pp. 431-445). Springer.

Trafford, V., \& Leshem, S. (2008). Stepping stones to achieving your doctorate: By focusing on your viva from the start. McGraw-Hill Education (UK).

Van der Vaart, G., van Hoven, B., \& Huigen, P. P. (2018, May). Creative and arts-based research methods in academic research. Lessons from a participatory research project in the Netherlands. Paper presented at the Forum Qualitative Sozialforschung/Forum. Qualitative Social Research, 19(2) Art.19.

Wall, C. R. G. (2016). From student to teacher: Changes in preservice teacher educational beliefs throughout the learning-to-teach journey. Teacher Development, 20(3), 364379.

Williams, J., Ritter, J., \& Bullock, S. M. (2012). Understanding the complexity of becoming a teacher educator: Experience, belonging, and practice within a professional learning community. Studying Teacher Education, 8(3), 245-260.

Wood, W. (1995). Weaving the warp and weft of occupational therapy: An art and science for all times. American Journal of Occupational Therapy, 49(1), 44-52. 